\title{
Bile Secretion Inhibition
}

National Cancer Institute

\section{Source}

National Cancer Institute. Bile Secretion Inhibition. NCI Thesaurus. Code C41488.

Bile Secretion Inhibition consists of interference with, or restraint of, activities involved in release from the gallbladder into the duodenum of an emulsifying agent (bile) produced in the liver that contains bile acids and salts, cholesterol, and electrolytes and that aids digestion of fats. 